\title{
BLICKDIAGNOSE
}

\section{Spontaner Schiefhals}

\section{Hier half nicht mal Botox}

\section{Der 33-jährige Mann stellte sich vor einigen Wochen in der Praxis mit einem spontan auf- getretenen Schiefhals vor.}

- Als er meine Praxis aufsuchte, bestand dieser schon drei Monate. Alle bisher durchgeführten Therapien wie Krankengymnastik, muskelentspannende Medikamente, manuelle Therapie, Halskrause, Infiltrationen mit Lokalanästhetika und Wärmeanwendungen blieben ohne Erfolg. Selbst die zuletzt mehrfach durchgeführten Botoxinfiltrationen beim Neurologen halfen nicht. Inwieweit neben einer muskulären Komponente vielleicht auch psychosomatische Beschwerden die Ursache sein könnten, ist nicht ganz klar. Der Patient hatte kurz nach dem ersten Auftreten seinen Arbeitsplatz verloren. Verständlicherweise klagt er nun auch zunehmend über Schwindel und Sehstörungen aufgrund des Schiefhalses. Leider konnte trotz intensiver Einbindung verschiedener Fachdisziplinen und Physiotherapeuten noch keine Besserung erzielt werden.

\section{Haben Sie einen Therapievorschlag?}

Schreiben Sie uns!
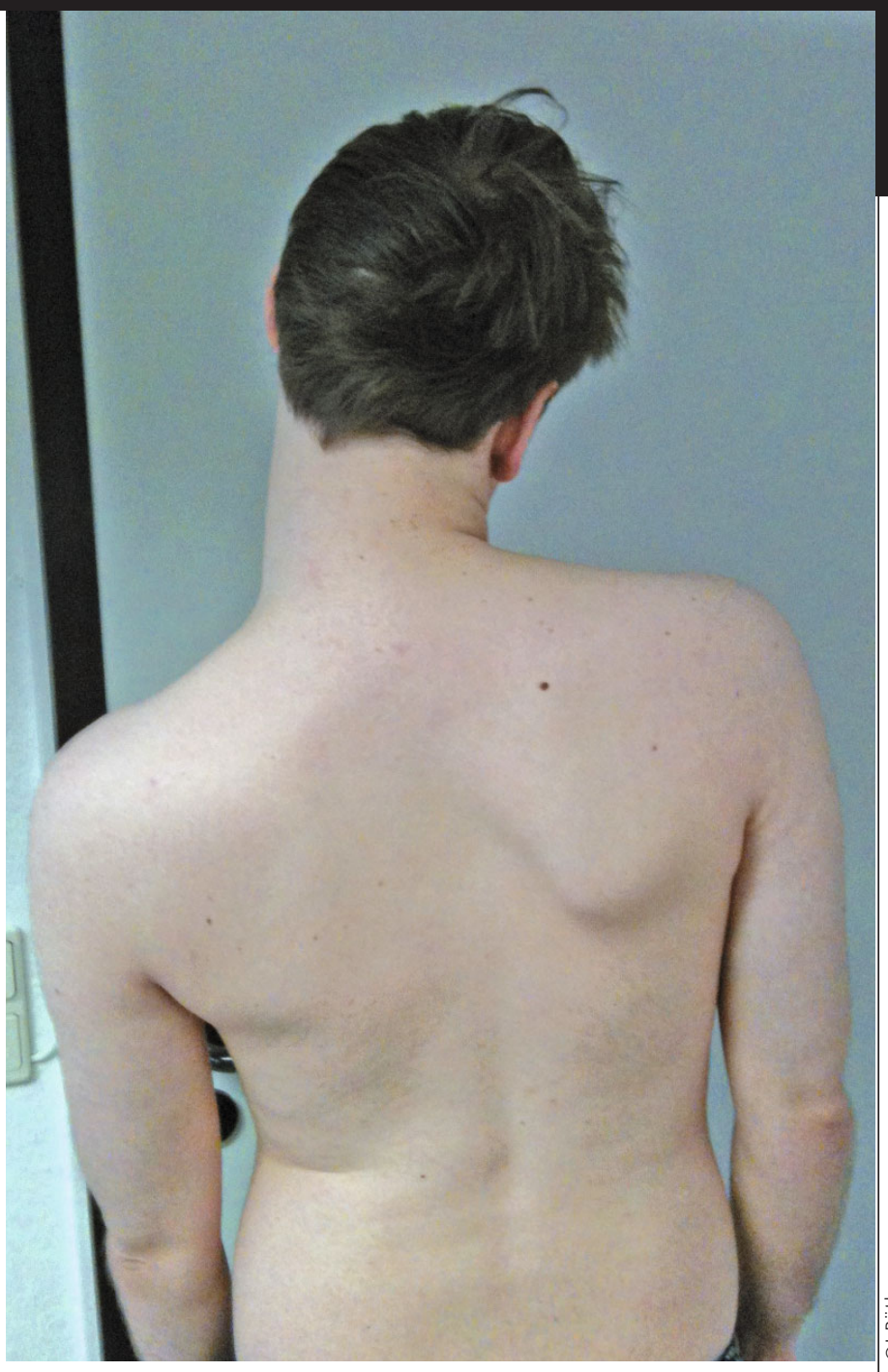

Keywords: torticollis

- Dr. med. Jens Rüthemann, MBA - Facharzt für Allgemeinmedizin, Am Kindergarten 2a, D-49843 Uelsen

\section{Ihr besonderer Fall?}

\section{Stellen Sie uns Ihren Fall vor}

Sicher sehen auch Sie ab und an einen besonders eindrucksvollen Befund in Ihrer Praxis. Fotografieren Sie ihn, schreiben Sie uns unter dem Stichwort Blickdiagnose, bei Veröffentlichung erhalten Sie 100 Euro.

MMW-Fortschritte der Medizin

E-Mail: reinhold.manhart@springer.com

Fax: 089/203043-31424 